\title{
Space Flight Qualification Program for the AMS- 02 Commercial Cryocoolers
}

\author{
K. A. Shirey, I. S. Banks, S. R. Breon, and R. F. Boyle \\ NASA/Goddard Space Flight Center \\ Greenbelt, MD 20771
}

\begin{abstract}
The Alpha Magnetic Spectrometer-02 (AMS-02) experiment is a state-of-the-art particle physics detector containing a large superfluid helium-cooled superconducting magnet. Highly sensitive detector plates inside the magnet measure a particle's speed, momentum, charge, and path. The AMS-02 experiment will study the properties and origin of cosmic particles and nuclei including antimatter and dark matter. AMS-02 will be installed on the International Space Station on Utilization Flight-4. The experiment will be run for at least three years.

To extend the life of the stored cryogen and minimize temperature gradients around the magnet, four Stirling-cycle Sunpower M87N cryocoolers will be integrated with AMS-02. The cryocooler cold tip will be connected via a flexible strap to the outer vapor cooled shield of the dewar. Initial thermal analysis shows the lifetime of the experiment is increased by a factor of 2.8 with the use of the cryocooler.

The AMS-02 project selected the Sunpower M87 cryocoolers and has asked NASA Goddard to qualify the cryocoolers for space flight use. This paper describes the interfaces with the cryocoolers and presents data collected during testing of the two engineering model cryocoolers. Tests include thermal performance characterization and launch vibration testing. Magnetic field compatibility testing will be presented in a separate paper at the conference.
\end{abstract}

\section{INTRODUCTION}

Since November 2001, two Sunpower M87 engineering model cryocoolers have been under test at NASA Goddard for the Alpha Magnetic Spectrometer-02 (AMS-02) International Space Station Project. NASA Goddard will be qualifying four Sunpower M87 cryocoolers for space flight use and two cryocoolers for flight spares on AMS-02. Delivery of the flight cryocoolers to Goddard is expected at the end of 2002.

The engineering model cryocoolers have undergone extensive thermal characterizations and magnetic compatibility testing. Engineering model number two has undergone electrical characterizations and vibration qualification.

\section{INSTRUMENT DESCRIPTION}

AMS-02 is scheduled to be launched in January 2006 and will be installed on the International Space Station (ISS) for a minimum three year mission. The experiment consists of 
a large superconducting magnet and a number of highly sensitive detectors that will measure a particle's speed, momentum charge, and patt in an effort to search space for the presence of dark matter, missing matter and antimatter.

The AMS-02 superconducting magnet will be cooled by 2,500 liters of superfluid helium in a large annular tank. The magnet, superfluid helium tank, layers of super-insulation and 4 vaporcooled shields are suspended within a toroidal vacuum case. The vacuum case is machined out of aluminum with two large support rings on the top and bottom of the outer cylinder. The cold mass is approximately $2,090 \mathrm{~kg}$.

Four Sunpower M87N cryocoolers will be used to cool the outer vapor cooled shield to extend the life of the stored cryogen. The baseline performance requirement is a total of 16 watts of heat lift at $80 \mathrm{~K}$ with less than 400 watts of input power. Initial thermal analysis shows the lifetime of the experiment is increased by a factor of 2.8 with the use of the cryocoolers. To minimize thermal gradients on the vapor cooled shield two cryocoolers will be mounted to 101.6 $\mathrm{mm}$ diameter ports on the upper vacuum case support ring and the remaining two cryocoolers will be mounted to the lower vacuum case support ring. Figure 1 shows a view of two of the cryocooler port locations on the AMS-02 vacuum case. The remaining two cryocooler port locations are 180 degrees from its pair on either support ring.

The cryocooler mounting brackets will thermally decouple the cryocooler from the vacuum case and provide a compliant (flexible, soft) mount in order to allow force attenuation using the passive balancer system.

The cold tip of the cryocoolers will be connected via a flexible strap to the outer vapor cooled shield of the dewar. Integration of the strap will be through a $101.6 \mathrm{~mm}$ diameter access port adjacent to the cryocooler mounting port. The strap will span a distance of approximately $100 \mathrm{~mm}$ and allow for relative motions no more than $12 \mathrm{~mm}$ between the cold tip and the vaporcooled shield. Motion of the strap is expected during launch, vacuum pump down, magnet cool down, magnet charging and discharging and in the case of a quench.

Each cryocooler will reject heat to a capillary pump loop sunk to a direct condensing zenith octagonal radiator. One quadrant of the radiator will be dedicated to each cryocooler.

The cryocoolers will be powered from either or both of the ISS $124 \mathrm{~V}$ dc busses (main and auxiliary). The electronics must provide the capability of being powered from either bus and must maintain galvanic isolation between the two busses. The power drive configuration has not yet been selected. Studies are being conducted on which waveform drive would be the most efficient.

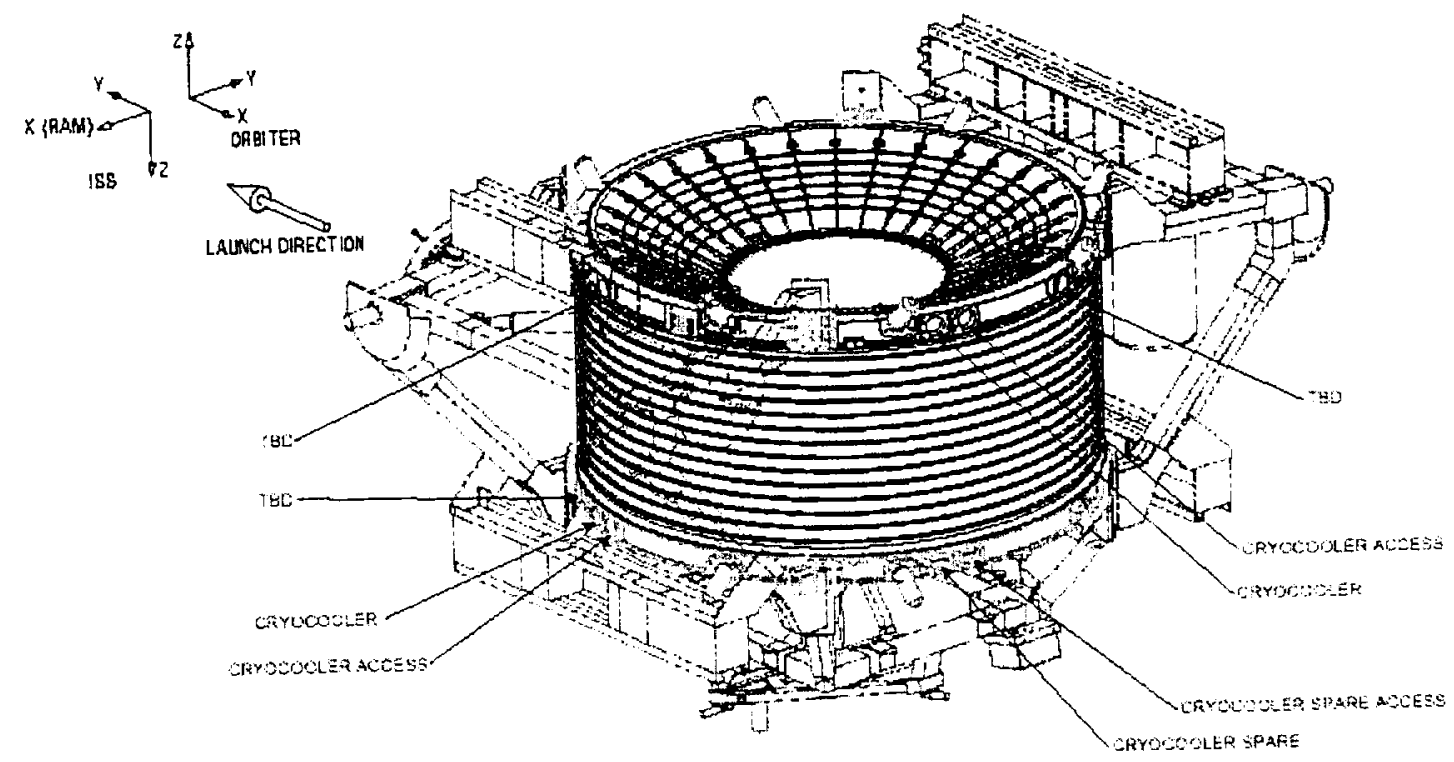

Figure. Cryocooler port locations on AMS-02 vacuum case. 
In order to eliminate beat frequencies, it is preferred that all cryocooler drive signals be synchronized. The pair of cryocoolers on the upper vacuum case ring will be run electrically in phase and the pair of cryocoolers on the lower vacuum case ring will be run electrically in phase. There is no phasing relationship between the pair of cryocooler on the upper vacuum support ring to the pair of cryocoolers on the lower support ring.

The cryocooler system has been allocated a maximum of 400 watts, which includes power to the electronics. Therefore, nominal operation will provide $100 \mathrm{~W}$ to the 4 cryocoolers. The maximum operational scenario will provide $150 \mathrm{~W}$ to 3 cryocoolers.

The cryocooler controller will monitor and maintain the following housekeeping parameters: cryocooler cold tip temperature, cryocooler case temperature, motor voltage, motor current, phase angle between the motor current and voltage, and cryocooler acceleration. The controller will provide automated shutdown in the event of an over-limit condition occurring with the heat reject temperature, motor current, and motor voltage. Ground station uplink commands will be available to enable/disable the launch lock mode and adjust the input voltage amplitude.

The complete cryocooler system design will be the combined work of a number of different organizations. The work is structured as follows:

- Cryocooler Drive Electronics and Controller: E.T.H. (Zurich, Switzerland)

- Cryocooler Mounting Bracket: Swales Aerospace (Beltsville, Maryland)

- Cryocooler Thermal Strap: Space Cryomagnetics Ltd. (Abingdon, England)

- Cryocooler Heat Rejection System: Carlo Gavazzi Space (Milano, Italy) and OHB Systems (Bremen, Germany)

\section{SUNPOWER M87 CRYOCOOLER}

The Sunpower M87 cryocooler is a commercial Stirling-cycle cryocooler. The compressor piston is driven by a moving-magnet linear motor. The amplitude of the input voltage to the linear motor controls the stroke of the compressor piston. A pressure wave is generated by the compressor piston and in turn drives the displacer piston. The displacer piston shuttles gas back and forth from the cold end to the warm end through a random fiber regenerator (SP past ICC). The gas is expanded in the cold end to absorb heat from the thermal load and compressed at the warm end to reject heat to the environment. A gas bearing system is utilized to center the compressor and displacer pistons and to prevent touch contact between the moving parts. Vibration suppression from the linear motor is implemented by the use of a passive (tuned spring-mass) balancer system. The compressor has a broad resonance around 60 hertz, while the balancer has a narrow resonance at 60 hertz.

The Sunpower M87 was designed to provide 7.5 watts of cooling at $77 \mathrm{~K}$ with 150 watts input power while operating at a $35^{\circ} \mathrm{C}$ heat reject temperature. The M87 has a designed lifetime of 40,000 hours. $^{2}$

The Sunpower M87 was designed specifically for liquefying oxygen for home-based portable oxygen therapy for the medical market. ${ }^{3}$ The M87 was not designed with space applications in mind. Cooler orientation during operation is restricted to the vertical orientation with the cold end facing down. Therefore, modifications were necessary to make the unit acceptable for space flight use. The Sunpower M87N was designed to operate in all orientations. In order to accommodate the generation of a sinusoidal waveform drive from the ISS $124 \mathrm{~V}$ dc bus, the motor impedance of the M87N was reduced in order to achieve a maximum of $75 \mathrm{~V}$ RMS. A flat mounting plate was added to the rear of the modified M87 cryocooler to allow simplified integration.

The AMS-02 project purchased both a standard Sunpower M87 and the modified M87N for the two engineering models. Before shipping the units to Goddard, each cryocooler was run by Sunpower for a 250 -hour qualification period. 


\section{Test Setup Description}

The coldfingers on EM\#1 and EM\#2 were instrumented with a heater to simulate a thermal load and a Lakeshore silicon diode then wrapped with 5 layers of MLI. RTDs mounted on the cryocoolers heat reject and cases monitored the environmental temperatures. The cryocoolers heat reject temperatures were maintained by laboratory recirculating chillers. EM\#1, tested in a vacuum chamber, was mounted in the vertical orientation cold finger down. EM\#2, tested on an optical bench, was mounted in the vertical orientation cold finger up. The coldfinger on EM\#2 was enclosed in a vacuum bonnet connected to a vacuum header. Both cryocooler mounts were designed to be compliant to allow force attenuation by the passive balancer.

Each engineering model cryocooler is protected with GSFC developed laboratory cryocooler shutdown electronics that protect against cold tip temperature overheat, cryocooler body temperature overheat, and loss of vacuum. The electronics display the total elapsed hours on the cryocooler and can be switched between a sinusoidal waveform drive and the Sunpower control electronics drive. The electronics allow for external input where an arbitrary waveform function generator and power amplifier combination could be used to produce a non-standard waveform. A data acquisition program created in LabVIEW data logs the input voltage, input current, input power, power factor, cryocooler body temperature and cryocooler cold tip temperature every minute.

\section{Thermal Characterizations}

Extensive thermal characterizations were conducted on both engineering model cryocoolers to measure the cold tip temperature as a function of input power to the compressor, heat reject temperature, and heat lift. Compressor power was measured at the input to the compressor; therefore power losses in the drive electronics are not reflected in the results. EM\#1 was tested with heat reject temperatures of $-10^{\circ} \mathrm{C}, 0^{\circ} \mathrm{C}, 20^{\circ} \mathrm{C}$, and $40^{\circ} \mathrm{C}$. EM\#2 tested with heat reject temperatures of $20^{\circ} \mathrm{C}$ and $40^{\circ} \mathrm{C}$. Both cryocoolers were tested with compressor power levels of $50 \mathrm{~W}, 75 \mathrm{~W}, 100 \mathrm{~W}, 125 \mathrm{~W}$, and $150 \mathrm{~W}$. Figures 1 and 2 demonstrate the thermal performance for $E M \# 1$ and EM\#2, respectively.

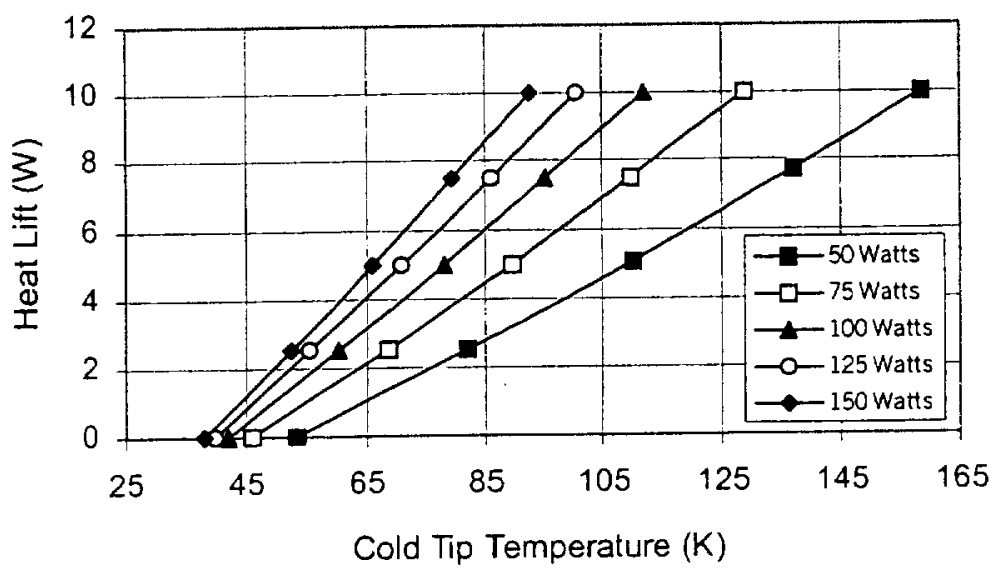

Figure 1. Thermal performance curves for EM\#1. 


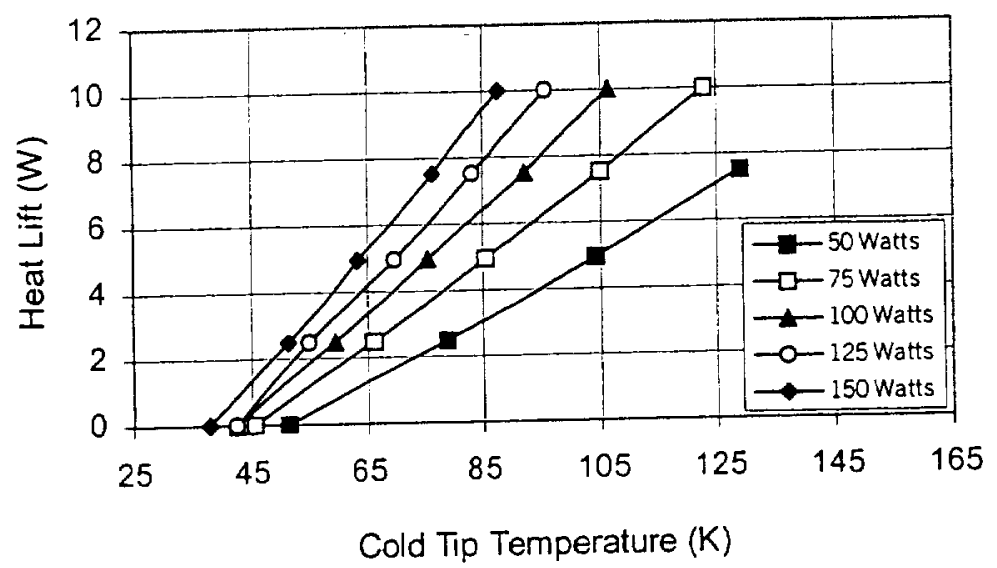

Figure 2. Thermal performance curves for EM\#2.

A subset of the thermal performance characterization is repeated at least every three months and compared against the baseline performance curve established during acceptance of the cryocooler to verify there has been no thermal performance degradation.

\section{Electrical Characterization}

A comparison study between different waveform drives and cryocooler efficiency was conducted on EM\#2. To date testing was done using a sinusoidal waveform and a square waveform. A pulse duration square wave will be studied later this summer.

Both the sinusoidal and the square waveform drives would use a PWM switching amplifier at $200 \mathrm{KHz}$. These methods will have switching losses as well as high EMI. The pulse duration square wave drive would eliminate the switching losses and result in lower EMI and higher efficiency.

A slight drop in efficiency was found when driving the cryocooler with a square wave. Table 1 shows the percent efficiency for both sinusoidal and square drive at nominal power.

Table 1. Cryocooler Efficiency Comparison With Different Waveform Drives

\begin{tabular}{|l|c|c|c|c|c|c|c|c|}
\hline $\begin{array}{c}\text { Drive } \\
\text { Type }\end{array}$ & $\begin{array}{c}\text { Load } \\
(\mathbf{W})\end{array}$ & $\begin{array}{c}\text { CTT } \\
(\mathbf{K})\end{array}$ & $\begin{array}{c}\text { Power } \\
(\mathbf{W})\end{array}$ & $\begin{array}{c}\text { Reject } \\
(\mathrm{K})\end{array}$ & $\begin{array}{c}\text { COP } \\
\text { (Carnot) }\end{array}$ & $\begin{array}{c}\text { COP } \\
\text { (Actual) }\end{array}$ & $\begin{array}{c}\% \\
\text { Efficiency }\end{array}$ & $\begin{array}{c}\% \\
\text { Cooling }\end{array}$ \\
\hline \hline Sin & 1.96 & 55 & 100 & 299 & 0.23 & 0.02 & 8.7 & 100 \\
\hline Square & 1.85 & 55 & 100 & 299 & 0.23 & 0.02 & 8.21 & 94.39 \\
\hline & & & & & & & & \\
\hline Sin & 4.95 & 75 & 100 & 299 & 0.33 & 0.05 & 14.78 & 100 \\
\hline Square & 4.88 & 75 & 100 & 299 & 0.33 & 0.05 & 14.57 & 98.59 \\
\hline & & & & & & & & \\
\hline Sin & 6.44 & 85 & 100 & 299 & 0.4 & 0.06 & 16.21 & 100 \\
\hline Square & 6.4 & 85 & 100 & 299 & 0.4 & 0.06 & 16.11 & 99.38 \\
\hline
\end{tabular}




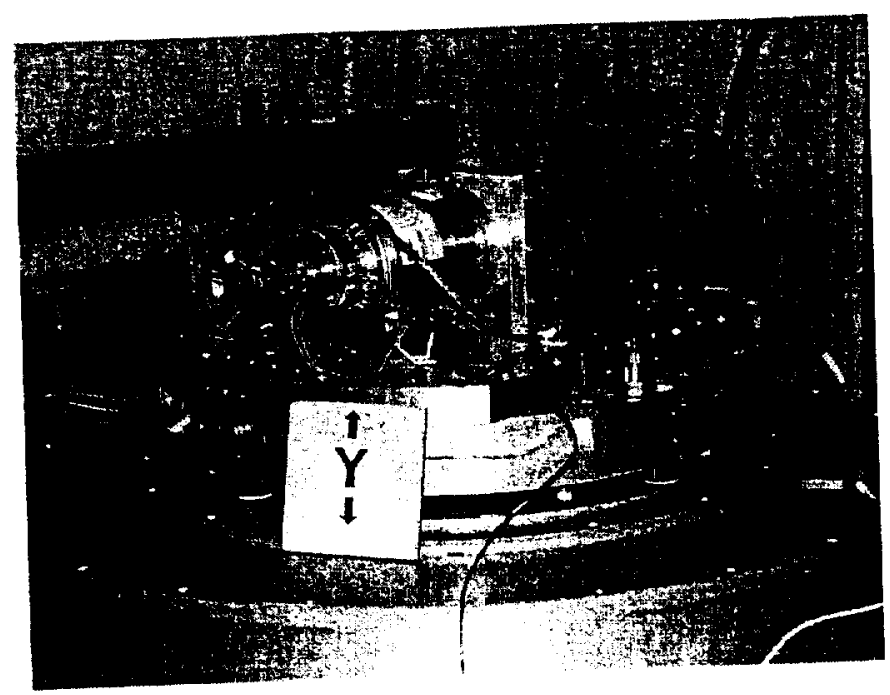

Figure 3. Random vibration test setup.

\section{Random Vibration}

To verify the $M 87 \mathrm{~N}$ design, launch vibration tests have been conducted on engineering model number two. The AMS-02 project expects that the vibration transmitted through the primary structure to the experiment components will be much smaller than minimum workmanship levels. The cryocooler mounted in a rigid mount with the motor coils shorted was subjected in three axes to a minimum workmanship level of $6.8 \mathrm{Grms}$. A Kistler three-axis accelerometer mounted to the cryocooler case collected the response data. Figure 3 shows EM\#2 mounted on the vibration shaker. Thermal performance testing pre- and post-vibration indicates there was no thermodynamic degradation as a result of random vibration testing.

Upon completion of the compliant mounting bracket design and machining, EM\#2 will be put through random vibration a second time to verify the integrity of the compliant mounting bracket.

\section{Cryocooler Trend Analysis}

A systematic trend analysis has been implemented to track the performance of EM\#1 and EM\#2 throughout the course of the project. The performance of the flight cryocoolers will be tracked using the same method.

Parameters being tracked are the hours of operation in a particular orientation, number of start/stop cycles, number and cause of an automatic shutdown for out-of-limit conditions including facility-related shutdowns, helium leak rate, and thermal performance.

Table 1 gives a summary of the trend analysis that has been recorded as of the end of May 2002. The total accumulated hours listed does not include the 250 hours accumulated on each unit before being shipped from Sunpower.

Table 1. EM Cryocoolers Trend Analysis Summaries

\begin{tabular}{|c|c|c|}
\hline Parameters & $\begin{array}{c}\text { Total Accumulated Trend } \\
\text { Values for EM\#1 }\end{array}$ & $\begin{array}{c}\text { Total Accumulated Trend } \\
\text { Values for EM\#2 }\end{array}$ \\
\hline $\begin{array}{c}\text { Hours of Operation in } \\
\text { Vertical Orientation }\end{array}$ & $2,225.5$ (cold finger down) & $2,590.5$ (cold finger up) \\
\hline $\begin{array}{c}\text { Hours of Operation in } \\
\text { Horizontal Orientation }\end{array}$ & 16.5 & 20.5 \\
\hline $\begin{array}{c}\text { Number of Starts/Stops } \\
\text { Automatic Shutdowns for } \\
\text { Out-of-Limit Conditions }\end{array}$ & 31 & 76 \\
\hline
\end{tabular}




\begin{tabular}{|c|c|c|}
$\begin{array}{c}\text { Thermal Performance } \\
\text { Verification }\end{array}$ & No change from baseline & No change from baseline \\
\hline Thermal Cycling & $0^{\circ} \mathrm{C}$ to $40^{\circ} \mathrm{C}$ & $20^{\circ} \mathrm{C}$ to $40^{\circ} \mathrm{C}$ \\
\hline Pressure Vessel Leak Rate & $10^{-8} \mathrm{std} \mathrm{cc} / \mathrm{sec}$ range & $10^{-8} \mathrm{std} \mathrm{cc} / \mathrm{sec}$ range \\
\hline Vacuum Flange Leak Rate & $10^{-9} \mathrm{std} \mathrm{cc} / \mathrm{sec}$ range & $10^{-9} \mathrm{std} \mathrm{cc} / \mathrm{sec}$ range \\
\hline Helium Gas Analysis & Not performed & Not performed \\
\hline
\end{tabular}

\section{SUMMARY}

During the past year, NASA Goddard has been testing two Sunpower M87 engineering model cryocoolers for the Alpha Magnetic Spectrometer-02 (AMS-02) International Space Station Project. The standard off-the-shelf M87 cryocooler was modified for space flight application.

The engineering model cryocoolers have just over 2,000 hours of accumulated run time. Extensive thermal performance characterizations have verified that four M87 cryocoolers will meet the AMS- 02 cooling requirement of $16 \mathrm{~W}$ of heat lift at $80 \mathrm{~K}$ with less than $400 \mathrm{~W}$ input power. EM\#2 was subjected to random vibration at minimum workmanship levels without degradation in thermodynamic performance. Electrical characterizations using various waveform drives is continuing in order to determine the most efficient method for driving the cryocoolers.

\section{REFERENCES}

1. Breon, S.R., "Operation of A Sunpower M87 Cryocooler in a Magnetic Field", Cryocoolers 12. not vet published.

2. http://www.sunpower.com/products/index.html.

3. Unger, R.Z., "The Advent of Low Cost Cryocoolers," Cryocoolers 11, Kluwer Academic/Plenum Publishers, New York (2001), pp. 79-86. 